\section{The change of music preferences following the onset of a mental disorder}

\author{
Stefan Gebhardt, ${ }^{1}$ Richard von Georgi2 \\ 1Department of Psychiatry and \\ Psychotherapy, University of Marburg; \\ 2Department of Music Science and Music \\ Education, University of Giessen; \\ International Psychoanalytic University \\ of Berlin, Germany
}

\section{Abstract}

A psychiatric population ( $\mathrm{n}=123)$ was examined on how music preferences had changed after the onset of a mental disorder. Most patients did not change their previous music preference; this group of patients considered music helpful for their mental state, showed more attractivity and enforcement as personality traits and used music more for emotion modulation. Patients who experienced a preference shift reported that music had impaired them during the time of illness; these patients showed less ego-strength, less confidence and less enforcement and used music less for arousal modulation. A third subgroup stopped listening to music completely after the onset of the mental disorder; these patients attribute less importance to music and also reported that music had impaired their mental state. They showed more ego-strength and used music less for emotion modulation. The results suggest that the use of music in everyday life can be helpful as an emotion modulation strategy. However, some patients might need instructions on how to use music in a functional way and not a dysfunctional one. Psychiatrists and psychotherapists as well as music therapists should be aware of emotion modulation strategies, subjective valence of music and personality traits of their patients. Due to the ubiquity of music, psychoeducative instructions on how to use music in everyday life plays an increasing role in the treatment of mental illness.

\section{Introduction}

The high impact of music on the mind and therefore on mental disorders is unequivocal. ${ }^{1}$ Since ancient times music has had therapeutical implications in many cultures. Neurophysiological studies demonstrated the impact of music on both the cortex and basal emotional systems. ${ }^{2}$ Thus, music is also able to act directly on emotion processing systems, without being involved in cognitive processes. Based on the fact that psychiatric patients often show a maladaptive use in emotion regulation strategies, ${ }^{3,4}$ and that the use of music in everyday life (UofM) seems to have a substantial impact on their mental health, 5,6 it may be hypothesized that psychiatric patients might also use music in a dysfunctional manner. The fact that some people listen to selfidentified sad music when they already feel sad, has been explained by the concept of mood enhancement, ${ }^{7-9}$ what normally results in helpful self-regulation, but may be - in some cases - unsuccessful resulting in even more negative feelings than before listening to sad music. ${ }^{9}$ It could also be shown that patients with a depressive major disorder are more oriented to the cues in sad music than healthy control subjects. 10 Thus, listening to sad and complex music during a depressive episode might impair the current mental state, especially in patients who are ruminating. ${ }^{11,12}$ However, UofM is a relatively new research field which is based on the qualitative studies by Tia DeNore.13,14 In the following years, many descriptive studies have shown the importance of UofM in everyday emotion regulation. ${ }^{15-17}$ Nevertheless, up to now only limited approaches exist to try to measure UofM directly via questionnaire. Especially, Saarikallio et al.18,19 connect different strategies of UofM for emotion regulation with the so-called mood management theory by Zillmann. ${ }^{20,21}$ According to this theory, people use media for a quantitative regulation of their positive and negative emotional affects. Contrary to this approach, von Georgi et al. define UofM in a more qualitative way and use the term emotion modulation instead of emotion or mood regulation.22-27 Emotion modulation emphasizes the unfocused qualitative aspects of UofM rather than the directed quantitative ones. This means that people use music more often for a qualitative modulation than for a simple intensification or attenuation of the strength of existing affect and emotion. It could be shown that different types of UofM strategies are connected with personality and health. Particularly, a high emotional personality uses music in everyday life for modulating an existing affect which leads to better health (mediator effect). Because of the limited number of studies, the role of music preference is still unclear, especially in groups of patients with mental disorders. Normally, music preferences developed during adolescence are relatively stable throughout one's whole life, if they are measured on a higher level (e.g. I like rock music) and not with a single item measure (e.g. I like the song $\mathrm{X}$ by the musician Y). $25,28-30$ Besides many different processes in adolescence, it seems that learned strategies of UofM in everyday life may also be an important cause for a stable specific
Correspondence: Stefan Gebhardt, RudolfBultman-Strasse 8,35033 Marburg, Germany. Tel.: +49.6222.552001 - Fax +49.6222.552912001. E-mail: Stefan.Gebhardt@uni-marburg.de

Key words: Music; emotion modulation; emotion regulation; mental disorders; preferences; psychiatry.

Acknowledgments: authors thank Prof. JürgenChristian Krieg for having supported this study on the patients of the Department of Psychiatry and Psychotherapy, University of Marburg/Germany. There was no funding of the study

Contributions: the authors contributed equally.

Conflict of interest: the authors declare no potential conflict of interest.

Received for publication: 27 December 2014

Revision received: 27 April 2015.

Accepted for publication: 28 April 2015.

This work is licensed under a Creative Commons Attribution NonCommercial 3.0 License (CC BYNC 3.0).

(C) Copyright S. Gebhardt and R. von Georgi, 2015 Licensee PAGEPress, Italy

Mental Illness 2015; 7:5784

music preference. ${ }^{22,25,31}$ It is important to notice that the results of the recent years have shown that there is no direct relation between a specifc music preference and health. ${ }^{5}$ Rather it seems that the learned UofM strategies act as a mediator variable: learning how to use a specific individual kind of music (music preference) to modulate an existing positive or negative affect and emotion leads to a better psychological well-being and health (mediator approach). ${ }^{5,32}$ A first study on psychiatric patients showed that patients with mental disorders generally use music in everyday life more for emotion modulation, in particular for the reduction of negative emotions, than healthy individuals, who prefer music more for fun stimulation. ${ }^{27,33}$ This may be interpreted as a protective behavior of patients with mental illness, although because of the missing empirical studies, it is still not clear whether this behavior has positive or negative consequences for the existing illness.

Taking into account the findings mentioned above, the maladaptive use of music for emotion and affect modulation may be possible in psychiatric patients. ${ }^{27}$ On the other hand, if these emotions modulation strategies are learned during the psychosocial development, it is difficult to change them suddenly without any therapeutic help at the onset of a psychological or psychiatric illness. From a psychological point of view, it is easier to change or 
avoid the kind of the stimuli (music) used within this special situation than this learned behavior strategy. Until now, to our knowledge, no study exists which examines the individual stability, change or avoidance of music to modulate existing affect and emotion in mental illness in connection to additional variables as personality and the UofM. Therefore, the aim of this subsequent investigation on a previously studied sample, 34 was to explore behavioral patterns of potential changes in music preferences following the onset of a mental disorder.

We purposely refer to the vague term mental disorder in order to focus on the crucial role of emotion modulation processes as a potential common (causative or concomitant) core feature of the entirety of all psychiatric and psychosomatic diseases.

Due to the ubiquity of music, psychoeducative instructions on how to deal with music in everyday life during mental illness should result in continously improving emotion modulation strategies in everyday life of patients. Music psychoeducation is still a new field of psychiatric treatment, but should play an enormous role in the therapy of mental disorders. The increasing knowledge of the patients should generate transfer effects for the daily routine, so that therapy effects should still increase, even when the therapy (in a stricter sense) has already finished.

\section{Materials and Methods}

Out of 312 patients admitted at the Department for Psychiatry and Psychotherapy of the University of Marburg, Germany, $n=190$ patients agreed to participate in the study carried out between 2005 and 2007. Inclusion criterion was the in- or outpatient treatment of a psychiatric disorder. Exclusion criteria were a severe or acute episode of a mental disorder or the missing consent for participating in the study. Data on music preferences for both before and after the onset of the mental disorder were available in $\mathrm{n}=123$ ( 71 female and 52 male; mean age $36.0 \pm 13.0$, range $19-80$ years). No patient in the study was treated with music therapy during the actual inpatient treatment. The patients suffered from mood disorders (36.6\%), neurotic disorders (26.0\%), disorders of adult personality and behavior (18.7\%), schizophrenia spectrum disorders $(8.1 \%)$, psychoactive substance use (5.7\%), and others. Gender and age within the study group did not correlate significantly. Patients gave written informed consent; the study was approved by the Ethics Committee of the University of Marburg, Germany.

Patients received self-assessment questionnaires. A questionnaire on music preferences with 16 forced choice categories on the back- ground of the study of Rentfrow and Gosling was used. ${ }^{29}$ The music preference categories are: reflexiv and complex (R\&C; jazz, classic, blues); rhythmical and energetic (R\&E; soul, funk, rap, hip-hop, techno, dance, latin, reggae); intensive and rebellious (I\&R; rock, hard rock, heavy metal, alternative, grunge) and upbeat and coventional (U\&C: pop, oldies, rock'n roll, country, soundtrack, german folk music, religious).

In addition, the Inventory for the assessment of Activation and Arousal modulation through Music (IAAM), the SelbstkonzeptInventar (SKI) and the Global Assessment of Functioning scale (GAF) were used. ${ }^{25,35-37}$ Further, we introduced an additional questionnaire with single questions on how emotion modulation was reached through music, on the valence of music for the patients, on drug abuse and on other relevant items. Further information on the sample, the instruments used and the study design is given in our last report. 34

Differences between patient groups were studied using t-tests and oneway variance analysis for continuous variables and chisquare test for dichotomous data. All P-values were two-tailed; 0.5 was the significance level. Because of the exploratory nature of this study, empirical P-values lower than 0.10 were also interpreted as an existing trend to control for beta error, and a correction for multiple testing was not included. The data were analyzed using Statistical Package of the Social Sciences (SPSS 21 for Windows) software.

\section{Results}

\section{Descriptive data}

Patients reported that they prefered the following music styles before/after the onset of their mental disorder versus during the time of the occurrence of mental symptoms: $R \& C$ 22.8/20.3\%; R\&E 13.0/6.5\%; I\&R 23.6/26.0\%; U\&C 39.0/31.7\%; no music 1.6/15.4\%.

The following preference shifts could be detected.

R\&C patients: $56 \%$ maintained their preference, $13 \%$ changed to I\&E, $3 \%$ to R\&E and $3 \%$ to $\mathrm{U} \& \mathrm{C}$, whereas $16 \%$ stopped listening to music.

$R \& E$ patients: $35 \%$ maintained their preference, $24 \%$ changed to U\&C, $12 \%$ to R\&C, $6 \%$ to I\&R, whereas $18 \%$ stopped listening to music.

I\&R patients: $65 \%$ maintained their preference, $6 \%$ changed to R\&C, $6 \%$ to U\&C, $3 \%$ to $\mathrm{R} \& \mathrm{E}$, whereas $6 \%$ stopped listening to music.

U\&C patients: $58 \%$ maintained their preference, $7 \%$ changed to R\&C, $5 \%$ to I\&R, whereas $16 \%$ stopped listening to music.

No music: 2 patients, who did not listen to music before the onset of the disorder started to prefer R\&C after its onset.

Patients with/without a preference shift or who discontinued listening to music did not differ in age, gender, diagnosis or psychosocial functioning.

The following subgroups of the patient sample can be differentiated with respect to music preference change after the onset of the mental disorder.

\section{No shift of music preference}

After the onset of the psychiatric disorder 80 patients (65.0\%) maintained their music preference.

In SKI scales patients with no shift showed more attractivity (trend; $\mathrm{t}=1.71$; $\mathrm{df}=111$; $\mathrm{P}=0.091$ ), more enforcement (trend; $\mathrm{t}=1.72$; $\mathrm{df}=109.5 ; \mathrm{P}=0.064$ ) and according to IAAM scales they used music more for cognitive problem solving (trend; $\mathrm{t}=1.73 ; \mathrm{df}=105$; $\mathrm{P}=0.086$ ) and reduction of negative activity (trend; $\mathrm{t}=1.91 ; \mathrm{df}=110 ; \mathrm{P}=0.058$ ) and more for arousal modulation $(\mathrm{t}=2.58 ; \mathrm{df}=94.1 ; \mathrm{P}=0.004)$ in comparison to the other patients.

Other variables: patients with no shift of music preference reported significantly more frequently that music has helped them $\left(\chi^{2}=16.70 ; \mathrm{df}=1 ; \mathrm{P}<0.001\right)$ when compared to patients with a shift.

\section{Preference shift}

Twenty-six patients (21.2\%) of the study population have undergone a preference shift $(\mathrm{n}=26 ; 21.1 \%)$.

In SKI scales the patients with a preference shift showed less ego-strength $(\mathrm{t}=-3.00$; $\mathrm{df}=52.7 ; \mathrm{P}=0.001)$, less confidence $(\mathrm{t}=-2.42$; $\mathrm{df}=110 ; \mathrm{P}=0.017$ ), less enforcement (trend; $\mathrm{t}=-1.92 ; \mathrm{df}=113 ; \mathrm{P}=0.057)$ and in IAAM scales less arousal modulation $(\mathrm{t}=-1.79 ; \mathrm{df}=58.0$; $\mathrm{P}=0.022$ ).

Other variables: patients with a preference shift reported more that music has impaired them during the time of illness in contrast to patients who remained on their preference after the onset of the psychiatric illness (trend; $\left.\chi^{2}=4.39 ; \mathrm{df}=1 ; \mathrm{P}=0.052\right)$; if patients who stopped listening to music were included to the patients with preference shift the chiquadrat-test became significant $\left(\chi^{2}=9.89\right.$; $\mathrm{df}=1 ; \mathrm{P}=0.004)$.

\section{Discontinuance of listening to music}

A third subgroup ( $\mathrm{n}=17 ; 13.8 \%)$ stopped listening to music completely after the onset of the disorder.

In SKI scales these patients showed more ego-strength $(\mathrm{t}=2.25 ; \mathrm{df}=107 ; \mathrm{P}=0.027)$. According to IAAM scales they used music less for cognitive problem solving $(\mathrm{t}=-2.19$; $\mathrm{df}=105 ; \mathrm{P}=0.031$ ) and less for reduction of negative activation $(\mathrm{t}=-2.64 ; \mathrm{df}=110$; $\mathrm{P}=0.010$ ) compared to the patients who continued to listen to music after the onset of the dis- 
order.

Other variables: in this discontinuation group music played a smaller role in their family $\left(\chi^{2}=4.57 ; \mathrm{df}=1 ; \mathrm{P}=0.036\right)$ and for themselves (trend; $\chi^{2}=4.11 ; \mathrm{df}=1 ; \mathrm{P}=0.073$ ), they described themselves less musical $\left(\chi^{2}=4.89\right.$; $\mathrm{df}=1 ; \mathrm{P}=0.036)$ and they had more often the feeling that music has impaired them $\left(\chi^{2}=9.16 ; \mathrm{df}=1 ; \mathrm{P}=0.008\right)$ and has not helped them $\left(\chi^{2}=25.52 ; \mathrm{df}=1 ; \mathrm{P}<0.001\right)$.

\section{Discussion}

\section{Regarding music as a helpful emo- tion modulation stimulus in per- sonal crisis}

It is well known that music taste is already well developed in early adolescence and crystallizes further during late adolescence and early adulthood. ${ }^{30}$ Music preference has a certain lifetime stability. It is therefore not farfetched that music preferences represent a stability (or resilience) factor for the emotion system of an individual and can be used in times of mental health crisis. Accordingly, most of the patients in our present sample considered music helpful, used it for emotion modulation during the time of the mental disorder and did not change their previous music preference. However, it is striking that, during times of mental symptoms, markedly more patients (15.4\%) do not listen to music than before the onset of the mental disorder (1.6\%). The analysis shows that it seems to be crucial as to how much importance the patients attached to music or what role music had played in their family of origin. If patients had not experienced helpful effects through the use of music before the onset of a mental disorder, they obviously tended to stop listening to music during the mental disorder. Thus, in the group of patients who discontinued listening to music after the onset of the mental disorder we found that music played a less important role in their family and for themselves as well as the assumption that music would more impair than help them. They also used music less for cognitive problem solving or reduction of negative activation. The fact that these patients dared to stop listening to music, is explainable by the increased ego-strength in this patient group, which allows them to assert their inner beliefs. Nevertheless it can not be excluded that one reason for the discontinuation of listening to music after the onset of the mental disorder might lie in the symptomatology itself such as protecting oneself from overstimulation and/or general weakness in daily functioning.

Interestingly, the analysis of the shift of each patient's preferred music style after the onset of the mental disorder showed that patients with I\&R (rock, heavy metal, alternative etc.) and U\&C (pop, folk music, religious etc.) preferences maintained their preference the most in contrast to individuals with other premorbid preferences. It could be speculated that these music styles might be the most helpful ones in mental disorders in connection with the modulation strategies learned. However, in the current investigation we found no significant differences in music preference between those individuals, who reported having used music that improved their mental condition, and those who used music which depressed themselves, both before and after the onset of the illness. This is in line with the state of research that there is no direct relation between a specific music preference and health, whereas the learned UofM strategies have a stronger relevance. 5,32 A positive valence of the music was reported much more often than a negative one in all music styles, especially in R\&C (jazz, classic, blues) (88\% before and $80 \%$ after onset of illness). For R\&E (soul, funk, Rap, hip-hop, techno, dance, latin, reggae) the special feature could be detected that after the onset of the illness no patient reported that this music depressed him or her.

\section{The role of personality traits}

Patients with personality traits of high adjustment features (less ego-strength, less confidence, less enforcement, less attractivity) rather refrain from adherence to their previous music preference and are open to a shift to another music style, but afterwards complain that music had impaired them during the time of illness. This suggests that these patients might not be able to use music in a functional manner, but in a dysfunctional one and this perhaps even due to the mental disorder. Music as a strong emotional stimulus might enforce present positive or negative cognitiveaffective cycles with either tendencies towards a well-balanced/happy or a depressed mood. According to the patient reports, music mostly enforced the positive cycle.

\section{The role of emotion modulation strategies}

According to the IAAM concept patients who have undergone a shift in their music preference used music less for arousal modulation, less for cognitive problem solving and less for reduction of negative activity than patients who had no shift. This might underline the hypothesis that this subgroup of patients has a reduced approach to music as a primarily emotional medium, whereas most patients with mental disorders use music for the reduction of negative emotions, especially patients who prefer R\&C. ${ }^{38}$ It cannot be excluded that some patients might have the feeling of improving their mood through catharsis effects (venting) whereas - in fact - they produce a longterm negative effect on their mental state. For example, patients with a depression might listen to complex, dramatic classical music with a feeling of a high identification; however, staying inherent to the emotional system, they cannot overcome this depressing mood, as long as they are not able to use music in a more functional way. Patients with a depressive disorder listened more to music for relaxation, ${ }^{27}$ whereas the IAAM-dimension cognitive problem solving perhaps would be more helpful. We found no associations between diagnostic groups and preferences.

In a further subsequent investigation, we found that patients, who could improve their mental state through music, used music more for cognitive problem solving and reduction of negative activity $(\mathrm{t}=4.47 / 4.96 ; \mathrm{df}=138 / 143$; $\mathrm{P}<0.001)$. This could imply that some patients are able to improve their mood by a more or less conscious use of helpful music, especially patients with personality features of high egostrength and orderliness. ${ }^{34}$ Interestingly, even patients who reported a positive subjective valence of the music they listen to, profited only from the music for their mental health, when using emotion modulation strategies to reduce negative affects, independent from psychosocial functioning or a specific personality trait. Patients with a negative subjective valence of music more often reported that music has not helped them $\left(\chi^{2}=4.62 ; \mathrm{df}=1\right.$; $\mathrm{P}=0.042)$, or even impaired their mental state $\left(\chi^{2}=10.64 ; \mathrm{df}=1 ; \mathrm{P}=0.004\right) .{ }^{39}$

This result also suggests that, for example, in depressive patients, a positive stimulation might not be helpful in that direct way as one would think. But it might be much more helpful - besides developing positive perspectives - to instruct them in emotion modulation strategies for the reduction of negative activity. This is in line with the results of the work of David Watson; 40 according to his theory, negative and positive emotions co-occur and do not obliterate each other. Thus, patients suffering from a major depression do not have to be stimulated positively, but need strategies to reduce negative emotions. The reduction of negative emotions by music is excessively used by patients with addiction disorders. 41

\section{The role of the level of psychoso- cial functioning}

We found no associations in the level of psychosocial functioning (GAF) with the presence of a preference shift or no shift or discontinuation of listening to music in this study sample. Thus, the preference seems to be less dependent on the psychosocial functioning in contrast to emotion modulation strategies, which are clearly increased in patients with a low psychosocial functioning level. ${ }^{27}$ In a subsequent investigation we found that patients who listened to music with a positive subjec- 
tive valence before the onset of the mental disorder, showed a better psychosocial functioning after the onset of the mental disorder than patients with a negative subjective valence of music $(\mathrm{t}=2.03 ; \mathrm{df}=159 ; \mathrm{P}=0.045) .{ }^{39}$

\section{Limitations and strength of the study}

The investigation has some limitations. One limitation is the cross-sectional, exploratory design. Therefore, causal relationships cannot be inferred. All data were assessed during the hospital stay of the patients, which means that particularly data of healthy periods are retrospective. The high number of missing data on preference within the origin sample $(n=190)$ may be attributed to the psychiatric disorder which was still present in the inpatients.

The strength of this study consists of the empirical approach under real world conditions based on an emotion modulation concept of the UofM.

\section{Conclusions}

Overall, the results suggest that the use of music in everyday life can be helpful as an emotion modulation strategy. However, some patients might need instructions on how to use music in a functional, and not dysfunctional way. For this reason, psychiatrists and psychotherapists as well as music therapists should be aware of emotion modulation strategies, subjective valence of music and personality traits of their patients. Psychoeduction how to use music in everyday life plays an increasing role in therapy, not only in music therapy, but also in psychotherapeutic interventions as well as in psychiatric nursing focussing on the everyday life of the patients.

\section{References}

1. Sherratt K, Thornton A, Hatton, C. Emotional and behavioural responses to music in people with dementia: an observational study. Aging Ment Health 2004;8: 233-41.

2. Panksepp J, Bernatzky G. Emotional sounds and the brain: the neuro-affective foundations of musical appreciation. Behav Processes 2002;60:133-55.

3. Joormann, J Gotlib, IH. Emotion regulation in depression: relation to cognitive inhibition. Cogn Emot 2010;24:281-98.

4. Yoon KL, Maltby J, Joormann J. A pathway from neuroticism to depression: examining the role of emotion regulation. Anxiety Stress Coping 2013;26:558-72.

5. Miranda D, Gaudreau P, Debrosse R, et al.
Music listening and mental health: variations on internalizing psychopathology. In: MacDonald R, Kreutz G, Mitchell L, eds. Music, health, and wellbeing. New York: Oxford University Press; 2012. pp. 513-529.

6. Chin TC, Rickard NS. Emotion regulation strategy mediates both positive and negative relationships between music uses and well-being. Psychol Music 2014;42:692713.

7. Thayer RE, Newman JR, McClain TM. Selfregulation of mood: Strategies for changing a bad mood, raising energy, and reducing tension. J Pers Soc Psychol 1994:67: 910-25.

8. Ter Bogt TFM, Mulder J, Raaijmakers QAW, Nic Gabhainn S. Moved by music: a typology of music listeners. Psychol Music 2014;36:1-17.

9. Van den Tol AJM, Edwards J. Exploring a rationale for choosing to listen to sad music when feeling sad. Psychol Music 2011;41:440-65.

10. Bodner E, Iancu I, Gilboa A, et al. Finding words for emotions: the reactions of patients with major depressive disorder towards various musical excerpts. Art Psychother 2007;34:142-50.

11. Garrido S, Schubert E. Adaptive and maladaptive attraction to negative emotions in music. Musicae Sci 2013;17:147-66

12. Van den Tol AJM, Edwards J. Listening to sad music in adverse situations: how music selection strategies relate to selfregulatory goals, listening effects, and mood enhancement. Psychol Music 2014: $1-22$

13. DeNora T. Music as a technology of self. Poetics 1999;27:31-56.

14. DeNora T. Music in everyday life. Cambridge: Cambridge University Press; 2000.

15. Sloboda JA, O'Neill SA, Ivaldi A. Functions of music in everyday life: an exploratory study using the experience sampling method. Music Sci 2001;5:9-32.

16. Juslin PN, Laukka P. Expression, perception, and induction of musical emotions: a review and a questionnaire study of everyday listening. J New Music Res 2004;33: 217-38.

17. North AC, Hargreaves DJ, Hargreaves JJ. Uses of music in everyday life. Music Percept 2004;22:41-77.

18. Saarikallio S, Erkkilä J. The role of music in adolescents' mood regulation. Psychol Music 2007;35:92-112.

19. Saarikallio S. Music in mood regulation: initial scale development. Musicae Sci 2008;12:291-309.

20. Zillmann D. Mood management through communication choices. Am Behav Sci 1988;31:327-70.

21. Zillmann D. Mood management in the context of selective exposure theory. In:. Roloff ME, ed. Communication Yearbook 23; 1999. pp 123-145.

22. von Georgi R, Grant P, von Georgi S, Gebhardt S. Personality, emotion and the use of music in everyday life: Measurement, theory and neurophysiological aspects of a missing link. Marburg: Der Andere Verlag; 2006.

23. von Georgi R, Göbel MC, Gebhardt S. Emotion modulation by means of music and coping behaviour. In: Haas R, Brandes $\mathrm{V}$, Eds. Music that works. Contributions of biology, neurophysiology, psychology, sociology, medicine and musicology. Wien: Springer; 2009. pp 301-319.

24. von Georgi R, Polat B. Emotion, personality, use of music in everyday life and musical preferences. In: Luck G, Brabant 0, eds. Proceedings of the 3rd International Conference on Music \& Emotion (ICME3). Jyväskylä: University of Jyväskylä, Department of Music (http://urn.fi/URN: NBN:fi:jyu-201305291829), 2013.

25. von Georgi R. Anwendung von Musik im Alltag: Theorie und Validierungsstudien zum IAAM. Marburg: Tectum-Verlag, 2013.

26. von Georgi R. Affectivity and the use of music in everyday life: examination of the validity of the inventory for the measurement of activation and arousal modulation through music by means of various psychological tests. In: On local vs. universal (109-118). Istanbul: DAKAM Publishing; 2014. pp 109-118.

27. Gebhardt S, Kunkel M, von Georgi R. Emotion modulation in psychiatric patients through music. Music Percept 2014;31:485-93

28. Holbrook MB, Schindler RM. Some exploratory findings on the development of musical tastes. J Consum Res 1989;16:11924.

29. Rentfrow PJ, Gosling SD. The do re mi's of everyday life: the structure and personality correlates of music preferences. J Pers Soc Psychol 2003;84:1236-56.

30. Mulder J, Ter Bogt TF, Raaijmakers QAW, et al. From death metal to R\&B? Consistency of music preferences among Dutch adolescents and young adults. Psychol Music 2010;38:67-83.

31. Schäfer T, Sedlmeier P. From the functions of music to music preference. Psychol Music 2009;37:279-300.

32. von Georgi R, Kunkel M, König C, Steinbrück J. Kann Musik auch krank machen? Ein kritischer Beitrag zur krankheitsfördernden Wirkung von jugendspezifischen Musikgenres. In: Kreuz G, Bernatzky G, eds. Musik und Gesundheit. Berlin: Springer Verlag; 2015. [In press].

33. Gebhardt S, von Georgi R. Music, mental 
disorder and emotional reception behavior. music therapy today. Vol. VIII. Dezember 2007. Available from: pdf-file: http://www.wfmt.info/Musictherapyworld/ modules/mmmagazine/issues/2008010809 3144/20080108100520/MTT8_3_Gebhardt Georgi.pdf

34. Gebhardt S, Kunkel M, von Georgi R. The use of music for emotion modulation in mental disorders: the role of personality dimensions. J Integr Psychol Ther 2014;2:5.

35. von Georgi R. Das Inventar zur Messung der Aktivations- und Arousal-Modulation mittels Musik (IAAM). In: Schramm H, ed.
Medien und Kommunikations-wisssenschaft - Sonderband 1 Musik und Medien. Baden-Baden: Nomos; 2007. pp 138-156.

36. von Georgi R, Beckmann D. Selbstkonzept-Inventar (SKI). Bern: Huber; 2004.

37. American Psychiatric Association. Diagnostic and statistical manual of mental disorders (DSM-IV-TR). 4th ed. Washington, DC: American Psychiatric Press; 2000.

38. Gebhardt S, Kunkel M, von Georgi R. The role of music preferences for emotion modulation in psychiatric patients. [Submitted]
39. Gebhardt S, Kunkel M, von Georgi R. Emotion modulation in everyday life and the subjective valence of music in mental disorders. In: Bryant ML, ed. Handbook of emotion regulation: processes, cognitive effects and social consequences. Nova Science Publishers; 2015.

40. Watson D. Mood and temperament. New York: Guilford Press; 2000.

41. Gebhardt S, Kunkel M, von Georgi R. Music helps addicted patients to reduce negative emotions in everyday life. Res J Drug Abuse 2014;1:1. 